Goldschmidt 2021 Abstract

https://doi.org/10.7185/gold2021.7774

\title{
The Si cycle in the Precambrian ocean
}

\section{XIN-YUAN ZHENG}

University of Minnesota - Twin Cities

Presenting Author: zhengxy@umn.edu

The Precambrian ocean was characterized by high silica concentrations as indicated by the presence of abundant quartzrich rocks including cherts and banded iron formations (BIFs), as well as evidence for widespread silicification of peritidal and subtidal sediments. In contrast to the modern silica cycle that is heavily influenced by biological processes, the one in the Precambrian ocean was predominantly controlled by abiological processes, notably, solubility of different Si-bearing phases and the balance between $\mathrm{Si}$ sources and sinks in the ocean at that time. Variations in the silica cycle in the Precambrian ocean therefore have unique implications for evolution of surface environments and life on the early Earth.

Here I present results from a suite of microbial and abiological experiments conducted to better understand $\mathrm{Si}$ isotope fractionation in systems pertinent to formation of Precambrian cherts and BIFs. These results provide a refined framework for interpreting Si isotope data recorded in Precambrian sedimentary rocks, thereby shedding new light on the silica cycle in early oceans. Specifically, based on the results from laboratory experiments, published $\mathrm{Si}$ isotope data from Precambrian sedimentary rocks indicate that $\mathrm{Fe}$-Si gels were one of important precursors of BIFs, consistent with recent claims based on detailed mineralogical studies on some of these rocks. This revised view that emphasizes the tight coupling of $\mathrm{Si}$ and $\mathrm{Fe}$ enables new constraints on cycling of a redox sensitive element $\mathrm{Fe}$ from a non-redox sensitive element $\mathrm{Si}$, and it also creates new venues for re-thinking the role of the Si cycle on other nutrient element cycles in early oceans. Through the improved mechanistic understanding of $\mathrm{Si}$ isotope fractionation from low temperature experiments, the long-term trend shown in Precambrian $\mathrm{Si}$ isotope records can be re-interpreted, and provides new insights into the secular change in continental weathering and reverse weathering. 